\title{
Optimization of solvent extraction conditions for total carotenoids in rapeseed using response surface methodology
}

\author{
Ling Wang ${ }^{1}$, Yun Liu ${ }^{1, *}$ \\ ${ }^{1}$ College of Life Science and Technology, Huazhong University of Science and Technology, Wuhan 430074, P. R. China. \\ Email: $\underline{\text { liuyunprivate@sina.com }}$
}

Received 10 May 2009; revised 16 May 2009; accepted 19 May 2009.

\begin{abstract}
The optimum total carotenoids (TC) extraction from rapeseed with solvent extraction method by UV-visible spectrophotometer determination was investigated by using response surface methodology (RSM). Extraction duration, repeated extraction cycles, solvent-solid ratio and extraction temperature were assumed to be the most important factors affecting solvent extraction for the determination of TC. Optimum solvent extraction conditions for maximizing the determination of TC were: extraction duration 7.3h, repeated extraction three times, ratio of solvent-solid (v/w, $\mathrm{mL} / \mathrm{mg}$ ) 29:1, extraction temperature $42^{\circ} \mathrm{C}$. Under the optimal conditions, the yield of TC was up to $4.79 \mathrm{mg} / 100 \mathrm{~g}$. The model had a satisfactory coefficient of $R^{2}(=$ 0.912 ) and verified experimentally. The results showed that the conditions were mild and useful for maximizing a quantitative spectrophotometer determination of TC in rapeseed.
\end{abstract}

Keywords: Carotenoids; Optimization; Solvent Extraction; Response Surface Methodology; Rapeseed

\section{INTRODUCTION}

Carotenoids are a group of phytochemical bioactive compounds that are responsible for different colors of various plants and microorganisms but not animals [1]. It has been found that carotenoids can play an important role in the prevention of various types of cancer as well as other important "lifestyle- related" diseases, such as cardiovascular disease and age-related macular degeneration due to their antioxidant activity $[2,3,4]$. In addition to being potent antioxidants some carotenoids also contribute to provitamin A function [5]. Although the chemistry properties of carotenoids have been extensively studied their bioavailability, metabolism and bio- logical functions are only investigated recently [6,7]. In recent years the antioxidant properties of carotenoids have become the major focuses for researches, particularly focused on the role of lycopene in human health $[8,9]$. About $90 \%$ of the carotenoids in the diet and human body are represented by $\beta$-carotene, $\alpha$-carotene, lycopene, lutein and cryptoxanthin [10].

As the increasing of health-conscious and the demand for carotenoids, researchers shifted their attentions from chemical synthesis to natural products isolated from plants and microorganisms biological sources $[11,12]$. Rapeseed containing around $40 \%$ oil is one of the most important vegetable oil materials in the world. The total production of rapeseed plant all over the world was 46.2 Mt in 2005 [13]. Rapeseed contains rich carotenoids, such as $\beta$-carotein, $\alpha$-carotein and lutein, which can contribute to prolong the rapeseed oil shelf life and increase oil nutrition [14,15]. Many effective methods for carotenoids extraction from biological sources have been intensively employed, such as solvent extraction, solid phase extraction (SPE) and supercritical fluid extraction (SFE) $[12,16,17]$. Above these methods, solvent extraction method is universally application for extraction total carotenoids (TC) because solvent extraction method is relative simple and low cost $[18,19,20,21]$. However, the extraction of TC from rapeseed was rarely reported so far.

The most commonly used techniques for TC detection are UV-visible spectrophotometry, mass spectrometry and hydrogen or carbon nuclear magnetic resonance spectroscopy $\left({ }^{1} \mathrm{H}-\mathrm{NMR},{ }^{13} \mathrm{C}-\mathrm{NMR}\right)$, coupled or not with chromatographic techniques [22,23]. Regardless of the technique utilized, carotenoid extraction is highly influenced by procedural variables such as type of sample, type and ratio of solvents, extraction duration, repeated extraction times, storage conditions, etc. Therefore, the objective of this work was to establish a solvent extraction method for a quantitative spectrophotometer determination of TC. Rapeseed was selected as representative due to its abundance all over the world. Response sur- 
face methodology (RSM) was employed to optimize the extraction conditions, which could maximize the determination of TC in rapeseed.

\section{MATERIALS AND METHODS}

\subsection{Materials}

Rapeseed (Brassica napus L.) was provided by Rapeseed Engineering Center of Huazhong University of Agriculture. The raw material consisted of moisture $2.9 \pm 0.05 \%$, kernel $73.4 \pm 0.26 \%$, and seed capsule $26.6 \pm 0.02 \%$. Hexamethylene, petroleum ether, chloroform, acetone and methanol were of analytic grade.

\subsection{Experimental Design}

Six extraction solvents of hexamethylene, petroleum ether, chloroform, acetone, methanol and mixture of petroleum ether and acetone were tested to select the most optimum extraction solution for TC extraction. 3-5 g rapeseed was grinded into powder in a glass mortar and screened with 100 mesh sieve. Portions of ground rapeseed powder of $50 \mathrm{mg}$ (dry weight) were transferred to $40 \mathrm{~mL}$ beakers added with $5 \mathrm{~mL}$ extraction solvent and wrapped with aluminum foil. The samples were constantly agitated (Sisatom magnetic agitator) according to the extraction duration, protected from light at room temperature $\left(23^{\circ} \mathrm{C}\right)$. In the preliminary study, variables affecting TC extraction were solid-solvent ratio, extraction duration, extraction repeated cycles and extraction temperature. Response surface methodology (RSM) was used to optimize the above parameters. A four-factor- five-level centre composite design was adopted to optimize the extraction conditions for analysis of the TC in rapeseed. The quadratic response surface model fitted Eq.1:

$$
Y=b_{0}+\sum_{i=1}^{k} b i X i+\sum_{i=1}^{k} b i i X_{i}^{2}+\sum_{i=1}^{k} \sum_{j\rangle i}^{k} b_{i j} X_{i} X_{j}+\mathrm{e}
$$

where $\mathrm{Y}$ standed for the total carotenoids yield, b0 denoted the model intercept, $i$ and $j$ were the linear and quadratic coefficients, respectively, bi, bii and bij were the regression coefficient, $\mathrm{k}$ was the number of factors studied and optimized in the experiment and e was the random error. Statistical Analysis System (SAS Institute Inc, Cary, NC, USA) was used to fit the second order polynomial equation to the experimental data.

The goodness of fit of the model was evaluated by the coefficient of determination $\left(\mathrm{R}^{2}\right)$ and the analysis of variance (ANOVA). Quadratic polynomial equations were attained by holding one of the independent variances at a constant value and changing the level of the other variables.

\subsection{Total Carotenoids Quantification}

After extraction, the samples were filtered on filter paper, their volume was made up to $3 \mathrm{~mL}$, and they were stored in an amber flask $(\sim 10 \mathrm{~mL})$ filled with $\mathrm{N}_{2}$. To determine the amount of total carotenoids extracted, UV-visible spectrophotometer (UNICO UV-2802, USA) was used for a spectral window between 380 and $750 \mathrm{~nm}$, in triplicate. The absorbance value of carotenoids extract was monitored at $445 \mathrm{~nm}$. The total carotenoids (TC) yield $(\mathrm{mg} / 100 \mathrm{~g})$ was calculated according to the following Eq.2:

$$
T C(m g / 100 g)=\frac{A \times y(m L) \times 10^{6}}{A_{1 c m}^{\%} \times 1000 \times w}
$$

where A was the absorbance value of extract at $445 \mathrm{~nm}$, y was the volume of extract, $A_{1 \mathrm{~cm}}^{\%}$ was the extinction coefficient of carotenoids, and $\mathrm{w}$ was the weight of rapeseed powder $(\mathrm{g})$.

\subsection{Verification of Model}

Optimizations of extraction conditions, including reaction temperature, solid-solvent ration, extraction duration, and extraction repeated cycles for maximizing a quantitative UV-visible spectrophotometer determination of TC in the rapeseed were calculated by using the predictive equation from RSM. The actual determination of TC was carried out by UV-visible spectrophotometer after extraction at the optimum conditions, and the result was compared to the predicted value.

\section{RESULTS AND DISCUSSIONS}

\subsection{The Effect of Extraction Solvents on TC Yield}

Six different extraction solvents, hexamethylene, petroleum ether, chloroform, acetone, methanol and petroleum ether/acetone mixture, were employed to choose the most suitable solvent for TC extraction from rapeseed. The experimental results were shown in Table 1.

It was indicated from Table 1 that the mixture solvent of petroleum ether and acetone $(1: 1, \mathrm{v} / \mathrm{v})$ was the most effective solvent for TC extraction from rapeseed. As known, rapeseed contains polar carotenoid such as lutein, and nonpolar carotenoids such as $\beta$-carotene and carotenoids ester, the former is easily dissolved in polar solvent (e.g. acetone) while the latter is easily dissolved in nonpolar solvent (e.g. petroleum ether). Therefore, the

Table 1. Effects of extraction solvent on TC yield.

\begin{tabular}{lc}
\hline \multicolumn{1}{c}{ Extraction solvents } & TC yield $(\mathrm{mg} / 100 \mathrm{~g})$ \\
\hline Hexamethylene & $0.617 \pm 0.065$ \\
Petroleum ether & $0.972 \pm 0.038$ \\
Chloroform & $2.110 \pm 0.052$ \\
Acetone & $2.438 \pm 0.063$ \\
Methanol & $2.312 \pm 0.075$ \\
Petroleum ether/acetone mix- & $3.890 \pm 0.093$ \\
ture $(1: 1, \mathrm{v} / \mathrm{v})$ & \\
\hline
\end{tabular}


mixture solvent of petroleum ether and acetone was most suitable solvent for the TC extraction from rapeseed among the tested solvents.

\subsection{Optimization of Extraction Conditions by RSM}

In our preliminary study, variables affecting TC extraction were solid-solvent ratio, extraction duration, extraction repeated cycles and extraction temperature. The optimum experiments were conducted by using a fivelevel-four-factor central composite design with twelve replicates at the central point. The coded and actual levels of the three variables in Table 2 were selected to maximize the UV-visible spectrophotometer determination of total carotenoids (TC).
Table 2. Coded and actual levels of four variables.

\begin{tabular}{ccccc}
\hline Factors & $\begin{array}{c}\text { Duration } \\
\left(X_{1}, \mathrm{~h}\right)\end{array}$ & $\begin{array}{c}\text { Repeated } \\
\text { cycle }\left(X_{2}\right)\end{array}$ & $\begin{array}{c}\text { Solid-solvent } \\
\text { ratio } \\
\left(X_{3}, \mathrm{~g} / \mathrm{mL}\right)\end{array}$ & $\begin{array}{c}\text { Temperature } \\
\left(X_{4},{ }^{\circ} \mathrm{C}\right)\end{array}$ \\
\hline $\mathrm{r}=2$ & 10 & $5^{\text {th }}$ & $1: 50$ & 60 \\
1 & 8 & $4^{\text {th }}$ & $1: 40$ & 50 \\
0 & 6 & $3 \mathrm{r}^{\mathrm{d}}$ & $1: 30$ & 40 \\
-1 & 4 & $2^{\text {nd }}$ & $1: 20$ & 30 \\
$-\mathrm{r}=-2$ & 2 & $1^{\text {st }}$ & $1: 10$ & 20 \\
$\triangle \mathrm{x}$ & 2 & 1 & 10 & 10 \\
\hline
\end{tabular}

Table 3 showed the treatments with coded levels and their experimental results of TC in rapeseed.

The TC yield ranged from $2.762 \mathrm{mg} / 100 \mathrm{~g}$ to $4.863 \mathrm{mg}$ $/ 100 \mathrm{~g}$, and the run=20 and the run=27 had the minimum

Table 3. Coded level combinations for a four-variable central composite orthogonal and rotatable design (CCD).

\begin{tabular}{|c|c|c|c|c|c|}
\hline Runs & $\mathrm{X} 1$ & $\mathrm{X} 2$ & $\mathrm{X} 3$ & $\mathrm{X} 4$ & $\mathrm{TC}(\mathrm{Y} 1, \mathrm{mg} / 100 \mathrm{~g})$ \\
\hline 1 & -1 & -1 & -1 & -1 & $3.046 \pm 0.061$ \\
\hline 2 & -1 & -1 & -1 & 1 & $3.726 \pm 0.053$ \\
\hline 3 & -1 & -1 & 1 & -1 & $3.192 \pm 0.047$ \\
\hline 4 & -1 & -1 & 1 & 1 & $4.006 \pm 0.035$ \\
\hline 5 & -1 & 1 & -1 & -1 & $3.999 \pm 0.018$ \\
\hline 6 & -1 & 1 & -1 & 1 & $3.110 \pm 0.009$ \\
\hline 7 & -1 & 1 & 1 & -1 & $3.665 \pm 0.016$ \\
\hline 8 & -1 & 1 & 1 & 1 & $3.898 \pm 0.024$ \\
\hline 9 & 1 & -1 & -1 & -1 & $4.226 \pm 0.034$ \\
\hline 10 & 1 & -1 & -1 & 1 & $4.140 \pm 0.018$ \\
\hline 11 & 1 & -1 & 1 & -1 & $3.123 \pm 0.017$ \\
\hline 12 & 1 & -1 & 1 & 1 & $2.760 \pm 0.005$ \\
\hline 13 & 1 & 1 & -1 & -1 & $3.314 \pm 0.032$ \\
\hline 14 & 1 & 1 & -1 & 1 & $4.325 \pm 0.029$ \\
\hline 15 & 1 & 1 & 1 & -1 & $4.348 \pm 0.034$ \\
\hline 16 & 1 & 1 & 1 & 1 & $3.935 \pm 0.015$ \\
\hline 17 & -2 & 0 & 0 & 0 & $4.437 \pm 0.012$ \\
\hline 18 & 2 & 0 & 0 & 0 & $4.088 \pm 0.011$ \\
\hline 19 & 0 & -2 & 0 & 0 & $4.542 \pm 0.065$ \\
\hline 20 & 0 & 2 & 0 & 0 & $2.762 \pm 0.002$ \\
\hline 21 & 0 & 0 & -2 & 0 & $3.664 \pm 0.041$ \\
\hline 22 & 0 & 0 & 2 & 0 & $4.135 \pm 0.036$ \\
\hline 23 & 0 & 0 & 0 & -2 & $3.159 \pm 0.025$ \\
\hline 24 & 0 & 0 & 0 & 2 & $3.834 \pm 0.015$ \\
\hline 25 & 0 & 0 & 0 & 0 & $4.768 \pm 0.023$ \\
\hline 26 & 0 & 0 & 0 & 0 & $4.805 \pm 0.025$ \\
\hline 27 & 0 & 0 & 0 & 0 & $4.863 \pm 0.031$ \\
\hline 28 & 0 & 0 & 0 & 0 & $4.763 \pm 0.015$ \\
\hline 29 & 0 & 0 & 0 & 0 & $4.822 \pm 0.028$ \\
\hline 30 & 0 & 0 & 0 & 0 & $4.719 \pm 0.017$ \\
\hline 31 & 0 & 0 & 0 & 0 & $4.768 \pm 0.021$ \\
\hline 32 & 0 & 0 & 0 & 0 & $4.805 \pm 0.018$ \\
\hline 33 & 0 & 0 & 0 & 0 & $4.343 \pm 0.014$ \\
\hline 34 & 0 & 0 & 0 & 0 & $4.712 \pm 0.010$ \\
\hline 35 & 0 & 0 & 0 & 0 & $4.802 \pm 0.034$ \\
\hline 36 & 0 & 0 & 0 & 0 & $4.779 \pm 0.016$ \\
\hline
\end{tabular}

and maximum yield, respectively. Using the designed experimental data (Table 3 ), the polynomial model de- scribing the correlation between TC yield and the four variables or conditions was obtained as follows: 
$\mathrm{TC}\left(\mathrm{Y}_{1}, \quad \mathrm{mg} / 100 \mathrm{~g}\right)=4.77896+0.034687 * \mathrm{X}_{1}-0.049457 * \mathrm{X}_{2}$ $-0.00073 * \mathrm{X}_{3}+0.097412 * \mathrm{X}_{4}-0.154353 * \mathrm{X}_{1} * \mathrm{X}_{1}+0.060615$ $* \mathrm{X}_{1} * \mathrm{X}_{2}-0.169996 * \mathrm{X}_{1} * \mathrm{X}_{3}-0.043019 * \mathrm{X}_{1} * \mathrm{X}_{4}-0.307039 * \mathrm{X}$ ${ }_{2} * \mathrm{X}_{2}+0.197118 * \mathrm{X}_{2} * \mathrm{X}_{3}-0.068865 * \mathrm{X}_{2} * \mathrm{X}_{4}-0.245239 * \mathrm{X}_{3} *$ $\mathrm{X}_{3}-0.027968 * \mathrm{X}_{3} * \mathrm{X}_{4}-0.345873 * \mathrm{X}_{4} * \mathrm{X}_{4}$

Table 4 showed the analysis of variance ( $F$-test) for this model, and the coefficient of determination $\left(R^{2}\right)$ was shown as $91.16 \%$. The regression analysis showed that $91.16 \%$ of the variations were explained by the model. This indicated that the accuracy and general availability of the polynomial model was good, analysis of the response trends using the model was considered to be rea- sonable.

The contour and three-dimensional plots presented in Figs. 1-6 were produced for each pair of factors, whereas the other two factors were taken as a constant at their middle level.

Fig. 1 shows the effects of extraction duration and repeated extraction cycle on the determination of TC in rapeseed. The maximum TC could be obtained with both extraction duration and repeated extraction cycle locating in the medium levels. Both Higher duration and extended extraction cycle resulted in the decrease of TC, which could be due to the equilibrium of TC dissolving

Tab1e 4. Analysis of variance.

\begin{tabular}{cccccc}
\hline Source & D. F. & Sum of Squares & Mean of Squares & F Value & $\operatorname{Pr}>\mathrm{F}$ \\
\hline Linear & 4 & 0.3153 & 0.0788 & 0.3677 & 0.8290 \\
Quadratic & 4 & 9.5318 & 2.3829 & 11.1137 & $0.0001^{* *}$ \\
Cross product & 6 & 1.2609 & 0.2101 & 0.9801 & 0.461 \\
Lack of fit & 10 & 4.4821 & 0.4482 & 23.8511 & 0.073 \\
Model & 14 & 11.1080 & 0.7934 & 5.7004 & $0.0035^{* *}$ \\
$R^{2}=0.9116$ & & Adj. $R^{2}=0.7193$ & & &
\end{tabular}

D. F. denotes degree of freedom; $* * \mathrm{p}<0.005$

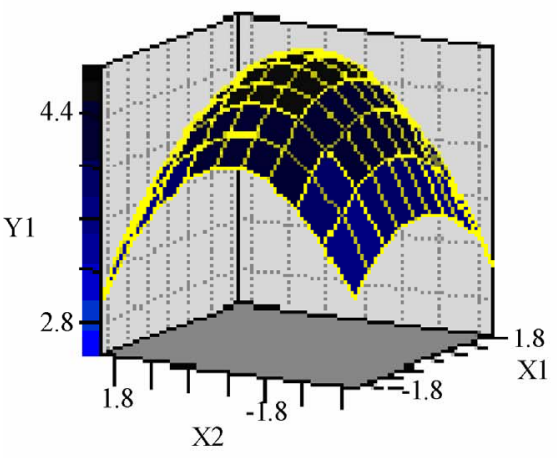

Fixed levels: $\mathrm{X} 3=0 \quad \mathrm{X} 4=0$

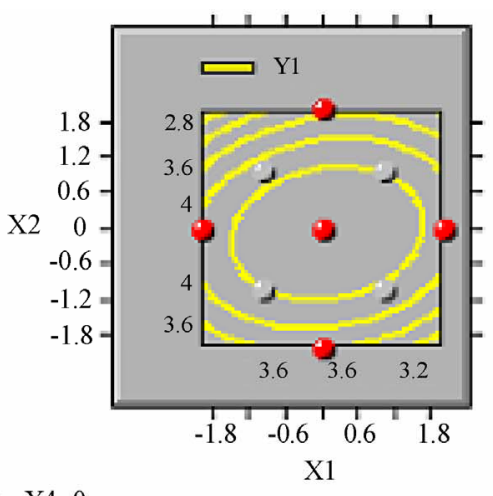

$\mathrm{X} 1$

$\left(\mathrm{X}_{1}\right.$ : duration $/ \mathrm{h} ; \mathrm{X}_{2}$ : repeated extraction cycle; $\mathrm{Y}_{1}$ : TC yield/(mg/100g))

Figure 1. Combined effect of duration and repeated extraction cycle on TC yield.
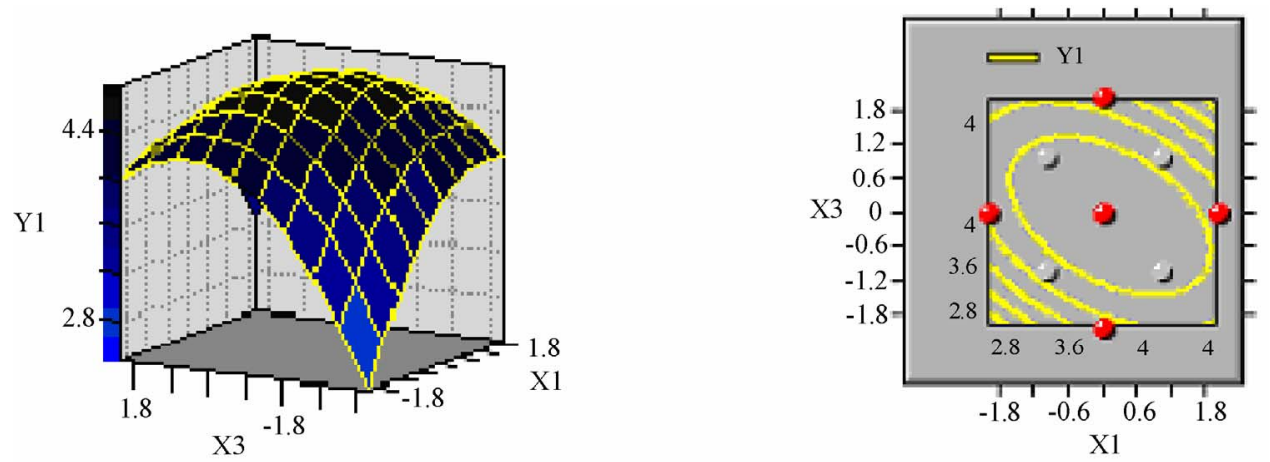

Fixed levels: $\mathrm{X} 2=0 \quad \mathrm{X} 4=0$

$\left(\mathrm{X}_{1}\right.$ : duration $/ \mathrm{h} ; \mathrm{X}_{3}$ :solid-solvent ratio/(g/mL); $\mathrm{Y}_{1}$ : TC yield/(mg/100g))

Figure 2. Combined effects of extraction duration and solid-solvent ratio on TC yield. 
into solvent obtained at $6 \mathrm{~h}$ and some other compounds also extracted together with TC with further increasing repeated extraction cycles.

Fig. 2 illustrated the effects of extraction duration and solid-solvent ratio on the determination of TC in rapeseed. The maximum TC was obtained with extraction duration locating at $6 \mathrm{~h}$ and solid-solvent ratio locating between 1:20 and 1:30. Higher extraction duration and solid-solvent ratio tended to result in a decrease of TC. This also could be due to the equilibrium of TC dissolving into solvent obtained at $6 \mathrm{~h}$ and some other compounds also extracted together with TC with further increasing extraction solvent.

Fig. 3 represented the effects of extraction duration and extraction temperature on the determination of $\mathrm{TC}$ in rapeseed. The maximum TC was obtained with extraction duration locating at $6 \mathrm{~h}$ and temperature locating between $40^{\circ} \mathrm{C}$ and $45^{\circ} \mathrm{C}$. Higher extraction duration and temperature led to a decrease of TC. The reason was that the equilibrium of TC dissolving into solvent was obtained at $6 \mathrm{~h}$ and the cateronoids was degraded at higher temperature.
Fig. 4 showed the effects of extraction repeated cycles and solid-solvent ratio on the determination of TC in rapeseed. The maximum TC was obtained with the extraction repeated cycles at three times and solid-solvent ratio with $1: 30$.

Fig. 5 illustrated the effects of extraction repeated cycles and extraction temperature on the determination of TC in rapeseed. The maximum TC was obtained with extraction repeated cycles locating at three times and extraction temperature locating between $40^{\circ} \mathrm{C}$ and $45^{\circ} \mathrm{C}$.

Fig. 6 listed the effects of solid-solvent ratio and extraction temperature on the determination of TC in rapeseed. The maximum TC was obtained with solid- solvent ration locating at 1:29 and extraction temperature locating between $40^{\circ} \mathrm{C}$ and $45^{\circ} \mathrm{C}$.

From the shape of contour plots (Figs. 1-6), the interaction strength as well as the optimal values range of the independent variables could be observed. Therefore the contour plots are generally the graphical representation of the regression equation for the optimization of extraction conditions for TC extraction from rapeseed.
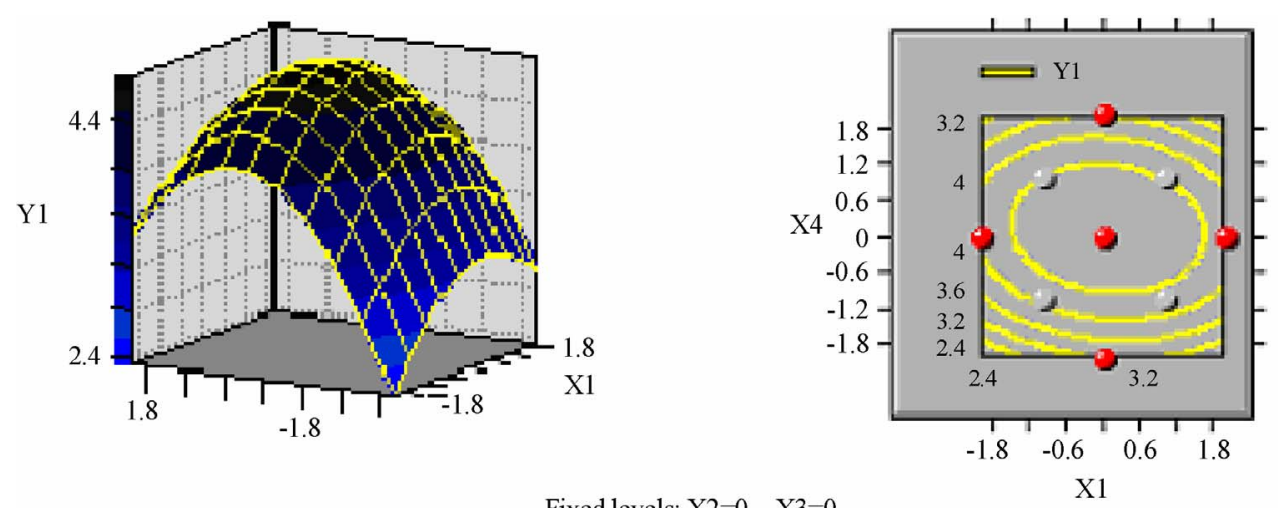

Fixed levels: $\mathrm{X} 2=0 \quad \mathrm{X} 3=0$

$\left(\mathrm{X}_{1}\right.$ : extraction duration $/ \mathrm{h} ; \mathrm{X}_{4}$ : extraction temperature $/{ }^{\circ} \mathrm{C} ; \mathrm{Y}_{1}: \mathrm{TC}$ yield $\left./(\mathrm{mg} / 100 \mathrm{~g})\right)$

Figure 3. Combined effects of extraction duration and extraction temperature on TC yield.
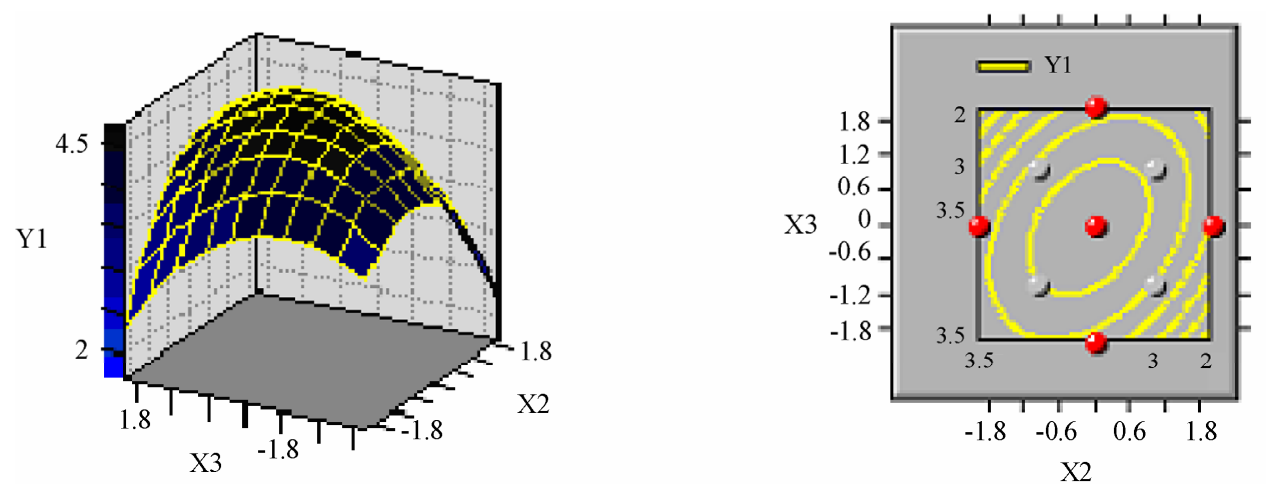

Fixed levels: $\quad \mathrm{X} 1=0 \quad \mathrm{X} 4=0$

$\left(\mathrm{X}_{2}\right.$ : repeated cycle; $\mathrm{X}_{3}$ : solid-solvent ratio/(g/mL); $\mathrm{Y}_{1}$ : TC yield $/(\mathrm{mg} / 100 \mathrm{~g})$ )

Figure 4. Combined effects of repeated cycles and solid-solvent ratio on TC yield. 


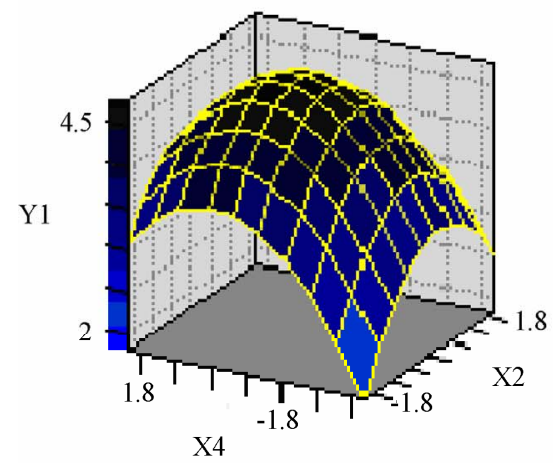

$\mathrm{X} 4$

Fixed levels: $\mathrm{X} 1=0 \quad \mathrm{X} 3=0$

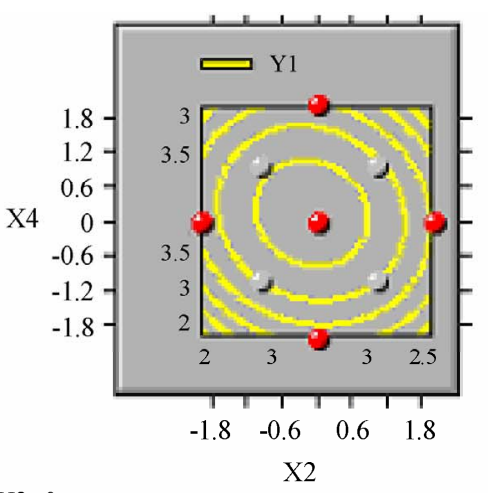

$\mathrm{X} 2$

$\left(\mathrm{X}_{2}\right.$ : repeated cycle; $\mathrm{X}_{4}$ : temperature $/{ }^{\circ} \mathrm{C} ; \mathrm{Y}_{1}: \mathrm{TC}$ yield $\left./(\mathrm{mg} / 100 \mathrm{~g})\right)$

Figure 5. Combined effects of repeated cycle and temperature on TC yield.
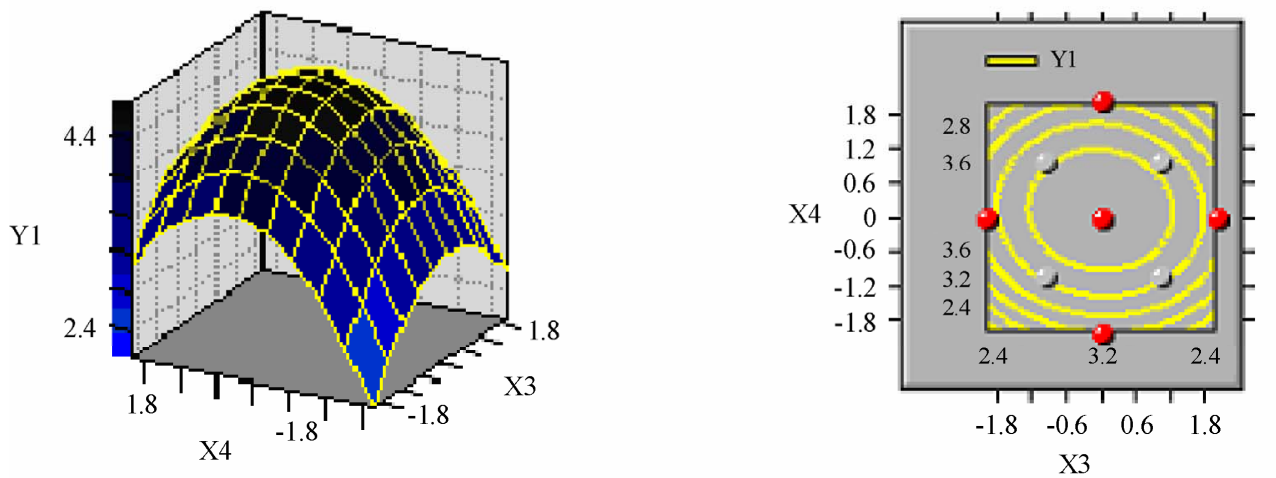

Fixed levels: $\mathrm{X} 1=0 \quad \mathrm{X} 2=0$

$\left(\mathrm{X}_{3}\right.$ : solid-solvent ratio/(g/mL); $\mathrm{X} 4$ : temperature $/{ }^{\circ} \mathrm{C} ; \mathrm{Y}_{1}$ : TC yield/(mg/100g))

Figure 6. Combined effects of solid-solvent ratio and temperature on TC yield.

\subsection{Verification of the Model}

The optimal parameters for TC extraction from rapeseed were evaluated by RSM and a maximal TC yield of $4.791 \mathrm{mg} / 100 \mathrm{~g}$ could be achieved at the optimal conditions: extraction duration $7.3 \mathrm{~h}$, repeated cycles $3 \mathrm{rd}$, solid-solvent ratio $1: 29$, extraction temperature $42^{\circ} \mathrm{C}$. The accuracy of the model was validated with triplicate experiments. The experimental value of TC yield was $4.77 \pm 0.02 \mathrm{mg} / 100 \mathrm{~g}$, which agreed well with the predicted value $(4.79 \mathrm{mg} / 100 \mathrm{~g})$, which relative error between experimental value and predicted value was 0.42 $\pm 0.04 \%$. The verification studies proved that the predicted value of TC for the model could be realistically achieved within a $95 \%$ confidence interval of experimental values. Therefore, the model from central composition design was considered to be accurate and reliable for predicting TC yield extraction from rapeseed.

\section{CONCLUSIONS}

Response surface method was proved to be a powerful tool for the optimization of extraction conditions for TC extraction from rapeseed. The conditions were optimized using a five-level-four-factor central composite design. Under optimal conditions (duration 7.3h, repeated cycle $3^{\text {rd }}$, solid-solvent ratio $1: 29$, extraction temperature $42^{\circ} \mathrm{C}$ ), the value of the yield of carotenoids was $4.79 \mathrm{mg}$ $/ 100 \mathrm{~g}$. Validation experiments were also carried out to verify the availability and the accuracy of the model, and the result showed that the predicted value was in well agreement with the experimental value.

\section{ACKNOWLEDGEMENT}

The authors are very thankful for Dr. Lin Qinxiong for providing UVvisible spectrophotometer in the experiments.

\section{REFERENCES}

[1] Holden, J. M., Eldridge, A. L. and Beeeher, G. R. (1999) Carotenoid content of U.S. food: An update of the database. Journal of Food Composition and Analysis, 12(3), 169-196.

[2] Sotirios, K. and Vassiliki, O. (2006) Antioxidant properties of natural carotenoid extracts against the AAPH-initiated oxidation of food emulsions. Innovative Food Science and Emerging Technologies, 7(1), 132-139. 
[3] Jamal, J. and Chieri, K. (2006) Variation of lycopene, antioxidant activity, total soluble solids and weight loss of tomato during post harvest storage. Post harvest Biology and Technology, 41(2), 151-155.

[4] Rao, A. V. and Rao, L. G. (2007) Carotenoids and human health. Pharmacological Research, 55(3), 207-216.

[5] Meléndez-Martínez, A. J., George, B. and Isabel, M. V. (2007) Relationship between the colour and the chemical structure of carotenoid pigments. Food Chemistry, 101(3), $1145-1150$.

[6] Meléndez-Martínez, A. J., Vicario, I. M. and Heredia, F. J. (2007) Review: Analysis of carotenoids in orange juice. Journal of Food Composition and Analysis, 20(7), 638-649.

[7] Andrew, J. and Young, G. M. (2001) Antioxidant and prooxidant properties of carotenoids. Archives of Biochemistry and Biophysics, 385(1), 20-27.

[8] Adetayo, O. O. and Aluko, R. E. (2005) The anti-carcinogenic and anti-atherogenic effects of lycopene: A review. Trends Food Sci. Technol., 16(8), 344-350.

[9] Cano, A., Acosta, M. and Arnao, M. B. (2003) Hydrophilic and lipophilic antioxidant activity changes during on-vine ripening of tomatoes (Lycopersicon esculentum Mill). Post-harvest Biol. Technol., 28(1), 59-65.

[10] Akhtar, M. H. and Bryan, M. (2008) Extraction and quantification of major carotenoids in processed foods and supplements by liquid chromatography. Food Chemistry, 111(1), 255-261.

[11] Meléndez-Martínez, A. J., Vicario, I. M. and Heredia, F. J. (2007) Provitamin A, carotenoids and ascorbic acid contents of the different types of orange juices marketed in Spain. Food Chemistry, 101(1), 177-184.

[12] Gua, Z. X., Chen, D. M., Han, Y. B., Chen, Z. G. and Gu, F. R. (2008) Optimization of carotenoids extraction from Rhodobacter sphaeroides. LWT-Food Science and Technology, 41(6), 1082-1088.

[13] FAO (2006) Statistical year book. Food and Agriculture Organization of the United Nations, 2/1,2/2, Rome.

[14] Haila, H. and Heinonen, M. (1994) Action of $\beta$-carotene on purified rapeseed oil during light storage. Food Sci- ence and Technology, 27(6), 573-577.

[15] Hornero-Méndez, D. and Mínguez-Mosquera, M. I. (2007) Bioaccessibility of carotenes from carrots: Effect of cooking and addition of oil. Innovative Food Science \& Emerging Technologies, 8(3), 407-412.

[16] Rodriguez-Amaya, D. B., Kimura, M., Godoy, H. T., and Amaya-Farfan, J. (2008) Updated Brazilian database on food carotenoids: Factors affecting carotenoid composition. Journal of Food Composition and Analysis, 21(6), 445-463.

[17] Simkin, A. J., Moreau, H., Kuntz, M., Pagny, G., Chenwei, L., Tanksley, Se., and McCarthy, J. (2008) An investigation of carotenoid biosynthesis in Coffea canephora and Coffea Arabica. Journal of Plant Physiology, 165(10), 1087-1106.

[18] Sachindra, N. M. and Mahendrakar, N. S. (2005) Process optimization for extraction of carotenoids from shrimp waste with vegetable oils. Bioresource Technology, 96(10), 1195-1200.

[19] Sheetal, M. C. and Laxmi (2007) Enzyme aided extraction of lycopene from tomato tissues. Food Chemistry, 102(1), 77-81.

[20] Huang, W., Li, Z. S., Niu, H., Li, D. and Zhang, J. (2008) Optimization of operating parameters for supercritical carbon dioxide extraction of lycopene by response surface methodology. Journal of Food Engineering, 89(3), 298-302.

[21] Mateose, R. and Garcia-Mesa, J. A. (2006) Rapid and quantitative extraction method for the determination of chlorophylls and carotenoids in olive oil by high-performance liquid chromatography. Analytical and Bioanalytical chemistry, 385(7), 1247-1254.

[22] Rodriguez-Amaya, D. B. (2001) A guide to carotenoid analysis in foods. Washington, DC.: Ed. ILSI-International Life Sciences Institute.

[23] Schoefs, B. (2002) Chlorophyll and carotenoid analysis in food products. Properties of the pigments and methods of analysis. Trends in Food Science and Technolog., 13(11), 361-371. 